ORIGINAL RESEARCH

\title{
Real-Life Frequency of New-Onset Thrombocytopenia during Linezolid Treatment
}

\author{
Nicole Giunio-Zorkin and Glen Brown
}

\begin{abstract}
Background: Thrombocytopenia is a well-recognized adverse effect of linezolid; however, the frequency of this adverse effect during therapy has been variable across previous studies, and the associated risk factors are unclear.

Objectives: To identify the real-life frequency of new-onset thrombocytopenia due to linezolid and to determine the associated risk factors.

Methods: A retrospective observational cohort study was conducted among consecutive inpatients at a tertiary care hospital who received linezolid for a minimum of 5 days between January 2013 and August 2017. Data were extracted from electronic medical records obtained from a hospital database. Thrombocytopenia was defined as platelet count less than $100 \times 10^{9} / \mathrm{L}$ or a $50 \%$ reduction from baseline (i.e., before linezolid initiation). Risk factors were identified by comparing the characteristics of patients who experienced the adverse effect during linezolid therapy with those of patients who did not experience the adverse effect. Continuous data were analyzed with the $t$ test and categorical data with the $\chi^{2}$ test.

Results: A total of 102 patients were included (38 women, 64 men; overall mean age 50 years, standard deviation [SD] 21). The mean duration of linezolid therapy was 14 (SD 10) days. Thrombocytopenia occurred in 18 patients $(17.6 \%)$. Risk factors for the development of thrombocytopenia included mean duration of therapy (22 [SD 18] days versus 12 [SD 7] days; $p=0.023)$, renal replacement therapy ( $17 \%$ versus $4 \% ; p=0.032)$, renal impairment $(61 \%$ versus $32 \% ; p=0.021)$, and concomitant administration of unfractionated heparin $(50 \%$ versus $21 \%$; $p=0.013)$.

Conclusions: The real-life frequency of new-onset of thrombocytopenia in patients receiving linezolid for a minimum of 5 days was $17.6 \%$. Risk factors for linezolid-induced thrombocytopenia included prolonged duration of therapy, renal impairment, and concomitant unfractionated heparin.
\end{abstract}

Keywords: linezolid, thrombocytopenia, frequency, risk factor, renal impairment

\section{Can J Hosp Pharm. 2019;72(2):133-8}

\section{RÉSUMÉ}

Contexte : La thrombopénie est une réaction indésirable bien connue, induite par le linézolide; cependant, la fréquence de cette réaction indésirable pendant le traitement hvariait d'une étude à l'autre et on ignore quels sont les facteurs de risque associés à cet antibiotique.

Objectifs : Découvrir la fréquence réelle des nouveaux cas de thrombopénie causés par le linézolide et déterminer les facteurs de risque qui lui sont associés.

Méthodes : Une étude de cohorte observationnelle rétrospective a été menée auprès de patients hospitalisés consécutivement dans un hôpital de soins tertiaires, qui ont reçu du linézolide pendant au moins cinq jours entre janvier 2013 et août 2017. Les données ont été tirées des dossiers médicaux électroniques provenant d'une base de données d'un hôpital. La thrombopénie a été définie comme un taux de plaquettes de moins de $100 \times 10^{9} / \mathrm{L}$ ou comme une réduction de $50 \%$ de leur valeur initiale (c'est-à-dire, avant l'amorce du traitement au linézolide). Les chercheurs ont établi les facteurs de risque en comparant les caractéristiques des patients ayant subi la réaction indésirable pendant leur traitement au linézolide avec les caractéristiques des patients n'ayant pas subi cet effet indésirable. Les données continues ont été analysées à l'aide d'un test $t$ et les données catégoriques à l'aide d'un test de $\chi^{2}$.

Résultats : Au total, 102 patients ont été admis (38 femmes, 64 hommes; âge moyen de 50 ans, écart-type de 21). La durée du traitement au linézolide était de 14 jours (écart-type de 10). Dix-huit patients (17,6\%) ont souffert de thrombopénie. Parmi les facteurs de risque de thrombopénie, on comptait la durée moyenne du traitement (22 jours [écart-type de 18] contre 12 jours [écart-type de 7]; $p=0,023)$, le traitement de suppléance rénale $(17 \%$ contre $4 \% ; p=0,032)$, l'insuffisance rénale (61\% contre $32 \% ; p=0,021)$ et l'administration concomitante d'héparine non fractionnée ( $50 \%$ contre $21 \%$; $p=0,013$ ).

Conclusions : La fréquence réelle de nouveaux cas de thrombopénie parmi les patients recevant du linézolide pendant un minimum de 5 jours était de 17,6\%. Parmi les facteurs de risque de thrombopénie associés au linézolide, on mentionne l'allongement de la durée du traitement, l'insuffisance rénale et l'administration concomitante d'héparine non fractionnée.

Mots clés : linézolide, thrombopénie, fréquence, facteur de risque, insuffisance rénale 
This single copy is for your personal, non-commercial use only.

For permission to reprint multiple copies or to order presentation-ready copies for distribution, contact CJHP at publications@cshp.ca

\section{INTRODUCTION}

Inezolid is an oxazolidinone antibiotic with activity against Ldrug-resistant bacteria, including methicillin-resistant Staphylococcus aureus and vancomycin-resistant Enterococcus. ${ }^{1}$ Linezolid is not usually a first-line agent because of its adverse effect profile; instead, it is reserved for situations requiring its particular spectrum of activity. ${ }^{2}$ The toxic effects of linezolid include peripheral neuropathy, serotonin syndrome, and myelosuppression. ${ }^{3}$ Given the landscape of rising antimicrobial resistance rates, linezolid is an important therapeutic option, and understanding the risk of toxicity will help guide clinicians in its use. ${ }^{4}$

The manufacturer has reported that the percentage of patients treated with linezolid who experienced thrombocytopenia in clinical trials was $2.4 \%$ (range $0.3 \%$ to $10 \%$ ). ${ }^{3}$ Interestingly, postmarketing studies have reported higher rates of linezolidassociated thrombocytopenia, ranging from $15 \%$ to $50 \% .^{1,5-9}$ The onset of the thrombocytopenia has been reported to range from within 7 days of starting the drug until as long as 14 days after discontinuation. ${ }^{8}$ The exact mechanism of linezolid-induced thrombocytopenia has not yet been elucidated. Proposed mechanisms include suppression of release of platelets from mature megakaryocytes, ${ }^{10}$ oxidative damage of circulating platelets, ${ }^{11}$ and immune-mediated platelet destruction. ${ }^{12}$

Possible risk factors for linezolid-induced thrombocytopenia identified in the literature include a higher daily weight-based dose, ${ }^{1}$ concurrent renal insufficiency ${ }^{1,8}$ concurrent need for hemodialysis, ${ }^{8}$ prolonged treatment duration, ${ }^{6,8,13}$ elevated baseline leukocyte concentration, ${ }^{6}$ chronic liver disease, ${ }^{13}$ previous vancomycin use, ${ }^{14}$ low baseline leukocyte concentration, ${ }^{8}$ and low baseline serum protein concentration. ${ }^{8}$ In addition, higher predose (trough) concentration of linezolid in the plasma and higher values for area under the concentration-time curve (AUC) have been suggested as possible risk factors. ${ }^{15,16}$ The association of these risk factors with linezolid-induced thrombocytopenia has varied among studies. It is important to identify risk factors for thrombocytopenia, because such risk factors would help in identifying patients at greater risk for development of this adverse effect and thus in need of increased monitoring or consideration of alternative therapy. ${ }^{8}$ Fortunately, the thrombocytopenia is reversible upon discontinuation of the drug, ${ }^{17}$ but the risk of bleeding may be heightened during the period of low platelet concentration. $^{18}$

There is no consensus on the real-life frequency of new-onset linezolid-induced thrombocytopenia. The safety concerns of this side effect and the potential need for discontinuation of effective drug therapy warrant further exploration of its frequency and associated risk factors. The primary objective of this study was to determine the real-life frequency of new-onset thrombocytopenia in patients receiving linezolid for longer than 5 days. The secondary objective was to evaluate the risk factors potentially associated with linezolid-induced thrombocytopenia.

\section{METHODS}

This retrospective observational cohort study involved patients who received linezolid (intravenously or orally) for a minimum of 5 days at St. Paul's Hospital between January 2013 and August 2017. The study protocol was reviewed and approved by the Providence Healthcare Research Ethics Board. For this type of study, individual patient consent was not required.

Patients were identified from the hospital's electronic health care database, and all consecutive patients who took linezolid for a minimum of 5 days during the specified time period were screened for inclusion. Linezolid treatment days were consecutive, and each patient was included only once per admission, regardless of the number of discrete courses of linezolid therapy. Data from repeat admissions of the same patient were included in the analysis. Patients who were discharged on continuing linezolid therapy were evaluated only until the date of discharge. Patients were excluded if they had a platelet count less than $100 \times 10^{9} / \mathrm{L}$ at the time of linezolid initiation, a hematological disorder causing decreased platelet production or survival, bone marrow-suppressing chemotherapy within 2 weeks before linezolid, diagnosis of disseminated intravascular coagulopathy or below-normal fibrinogen concentration before or during linezolid therapy, or occurrence of hemorrhage at any site that was not caused by thrombocytopenia and that required transfusion of packed red blood cells or platelets. The target was a convenience sample size of about 100 patients.

Data were collected from patients' electronic health care records. The information collected included age; sex; weight; dose and route of administration of linezolid; duration of treatment; vancomycin therapy within the 2 weeks preceding linezolid therapy; concurrent administration of low-molecular-weight heparin (LMWH), unfractionated heparin (UFH), or piperacillin; renal replacement therapy; and indication for linezolid. Laboratory data extracted included serum creatinine, platelet count, total protein concentration, albumin concentration, C-reactive protein (CRP) concentration, total bilirubin concentration, and international normalized ratio. The values collected for these variables included baseline values (closest to and preceding initiation of linezolid) and the most aberrant values during linezolid treatment. Patients were identified as having renal impairment if they required renal replacement therapy or had elevated serum creatinine ( $>90 \mu \mathrm{mol} / \mathrm{L}$ for females; $>100 \mu \mathrm{mol} / \mathrm{L}$ for males), either at baseline or during linezolid treatment. In addition, the first platelet value that satisfied the definition of thrombocytopenia was collected, along with information about whether linezolid was stopped or the patient received a platelet transfusion. For patients with thrombocytopenia, the first normal platelet count after discontinuation of linezolid was recorded, if available. The number of days to the first thrombocytopenic platelet value, the lowest platelet value, and first normal platelet value were also recorded. 
Thrombocytopenia was defined as platelet count less than $100 \times 10^{\%} / \mathrm{L}$ cells or a $50 \%$ reduction from baseline. In the previous literature, definitions of thrombocytopenia have varied from a decrease in platelet count of at least $25 \%$ from baseline ${ }^{19}$ to a decrease of greater than $75 \%$ from baseline..$^{20}$ The definition of thrombocytopenia used in this study balances the risk of missing patients with clinically relevant thrombocytopenia with the risk of including patients who had non-clinically relevant thrombocytopenia.

Results are presented as mean values (with standard deviations [SDs]) or percentages. Continuous data were analyzed with the unpaired 2-tailed $t$ test and categorical data with the $\chi^{2}$ test; $p$ values less than 0.05 were considered significant.

\section{RESULTS}

A total of 102 patients (38 women and 64 men; overall mean age 50 [SD 21] years) were included in the study. The mean duration of linezolid therapy was 14 (SD 10) days. The platelet count declined from baseline sufficiently to meet the definition of thrombocytopenia in 18 patients. In 64 of the remaining 84 patients, the platelet count declined from baseline, but the reduction was insufficient to fulfill the definition of thrombocytopenia. The mean decreases in platelet concentration from baseline were $179(\mathrm{SD} 87) \times 10^{9} / \mathrm{L}$ (mean percentage decline $60 \%$ [SD 10\%]) among patients with thrombocytopenia and $60(\mathrm{SD} 59) \times 10^{\%} / \mathrm{L}$ (mean percentage decline 17\% [SD 15\%]) among patients without thrombocytopenia.

The frequency of thrombocytopenia was $17.6 \%$ (18/102). For patients with thrombocytopenia, the mean lag time to the first thrombocytopenic platelet value (relative to initiation of linezolid) was 16 (SD 12) days. The mean time to the lowest thrombocytopenic platelet value was 21 (SD 15) days. The first thrombocytopenic platelet value occurred within 14 days of initiation in 50\% (9/18) of the patients. Linezolid was stopped for $61 \%(11 / 18)$ of the patients with thrombocytopenia, and 1 patient received a platelet transfusion. The mean time to the first normal platelet value after discontinuation of linezolid was 6 (SD 5) days, based on data for 9 patients (data were unavailable for the other 9 patients).

The characteristics of patients with and without thrombocytopenia were compared. Patients with thrombocytopenia had a significantly longer duration of treatment, and significantly higher frequencies of renal impairment, renal replacement therapy, osteomyelitis, and concurrent UFH (Table 1). In addition, the presence of elevated serum creatinine during linezolid therapy was found significantly more frequently among patients with thrombocytopenia (Table 2).

\section{DISCUSSION}

In this study, the frequency of thrombocytopenia was $17.6 \%$, and risk factors for linezolid-induced thrombocytopenia included renal impairment, renal replacement therapy, osteomyelitis, longer duration of therapy, and concomitant UFH. Previous studies have identified renal impairment as a risk factor. ${ }^{1,5,7,8,15,20-23}$ About 30\% of linezolid administered is cleared unchanged through the kidneys, and the drug is otherwise metabolized by oxidation of the morpholine ring. ${ }^{3}$ Metabolism of linezolid forms 2 inactive metabolites that are renally cleared. ${ }^{3}$ In practice, the dose of linezolid is not adjusted on the basis of renal function, because the product monograph states that similar plasma concentrations of linezolid are achieved regardless of renal function. ${ }^{3}$ However, this statement in the monograph was based on data for a single 600-mg oral dose of linezolid, and Matsumoto and others ${ }^{22}$ have shown that patients with renal impairment have increases in linezolid trough concentrations and AUC. Higher plasma concentrations of linezolid have been identified as a risk factor for linezolid-induced thrombocytopenia. ${ }^{15,22}$ Furthermore, Brier and others $^{24}$ showed that patients with renal impairment have higher concentrations of the 2 metabolites of linezolid. Although the mechanism of linezolid-induced thrombocytopenia is poorly understood, the accumulation of linezolid or its metabolites in patients with renal impairment might explain the higher frequency of thrombocytopenia in association with renal insufficiency.

Prolonged duration of linezolid therapy has been associated with linezolid-induced thrombocytopenia ${ }^{5-8,13}$ Consistent with these findings, our study identified longer duration of therapy as a risk factor. Interestingly, the first thrombocytopenic platelet value occurred within 14 days of initiation in $50 \%$ of the patients. This outcome has been noted previously: in a study by Nukui and others, ${ }^{15}$ one-half of the patients in whom thrombocytopenia occurred experienced this adverse effect within 11 days of starting linezolid. We do not feel that the thrombocytopenia in our study population was due to the initial infection that warranted linezolid therapy, because the onset of the decline in platelets occurred after a minimum of 5 days of therapy (according to the study's inclusion criteria), by which time the infection should have started resolving. We did not stratify patients in terms of early- and late-onset thrombocytopenia and were therefore unable to assess risk factors for early-onset thrombocytopenia. Notably, the platelet count declined from baseline in most of the patients in this study. It appears that linezolid is likely to cause a drop in platelets; however, the significance and timing of the drop may depend on certain risk factors. Although prolonged duration of linezolid therapy is a risk factor, thrombocytopenia may occur earlier than 14 days after initiation. Health care professionals should remain vigilant in monitoring for thrombocytopenia for the entire duration of linezolid treatment.

Thrombocytopenia occurred more frequently among patients who were receiving concomitant UFH. We included in this study patients receiving concomitant LMWH and UFH study because many hospital inpatients receive one of these agents for prophylaxis of venous thromboembolism. If we had excluded 
Table 1. Characteristics of Patients with and without Thrombocytopenia

\begin{tabular}{|c|c|c|c|c|c|}
\hline \multirow[b]{2}{*}{ Characteristic } & \multicolumn{4}{|c|}{ No. $(\%)$ of Patients* } & \multirow[b]{2}{*}{$p$ Value } \\
\hline & \multicolumn{2}{|c|}{$\begin{array}{c}\text { With } \\
\text { Thrombocytopenia } \\
(n=18)\end{array}$} & \multicolumn{2}{|c|}{$\begin{array}{c}\text { Without } \\
\text { Thrombocytopenia } \\
(n=84)\end{array}$} & \\
\hline Sex, female & 5 & & \multicolumn{2}{|c|}{$33 \quad(39)$} & 0.36 \\
\hline Age (years) (mean \pm SD) & \multicolumn{2}{|c|}{$\begin{array}{l}5 \quad(28) \\
58 \pm 17\end{array}$} & \multicolumn{2}{|c|}{$49 \pm 22$} & 0.07 \\
\hline Weight $(\mathrm{kg})($ mean \pm SD) & \multicolumn{2}{|c|}{$69 \pm 16$} & & \pm 21 & 0.32 \\
\hline \multicolumn{6}{|l|}{ Linezolid route } \\
\hline Oral & 11 & $(61)$ & 56 & $(67)$ & 0.65 \\
\hline IV & 2 & $(11)$ & 10 & $(12)$ & 0.92 \\
\hline Both oral and IV & 5 & (28) & 18 & $(21)$ & 0.56 \\
\hline Linezolid dose $(\mathrm{mg} / \mathrm{kg})($ mean \pm SD) & \multicolumn{2}{|c|}{$9.1 \pm 2.1$} & \multicolumn{2}{|c|}{$10.1 \pm 2.8$} & 0.10 \\
\hline \multicolumn{6}{|l|}{ Linezolid dosage } \\
\hline $600 \mathrm{mg} \mathrm{BID}$ & 17 & $(94)$ & 82 & (98) & 0.47 \\
\hline $600 \mathrm{mg}$ BID to once daily & 1 & (6) & 2 & $(2)$ & 0.47 \\
\hline $\begin{array}{l}\text { Duration of linezolid therapy } \\
\text { (days) (mean } \pm \text { SD) }\end{array}$ & \multicolumn{2}{|c|}{$22 \pm 18$} & \multicolumn{2}{|c|}{$12 \pm 7$} & 0.023 \\
\hline $\begin{array}{l}\text { Vancomycin within preceding } \\
2 \text { weeks }\end{array}$ & 7 & (39) & 31 & (37) & 0.87 \\
\hline \multicolumn{6}{|l|}{ Concurrent medications } \\
\hline LMWH & 8 & $(44)$ & 33 & (39) & 0.69 \\
\hline $\mathrm{UFH}$ & 9 & $(50)$ & 18 & (21) & 0.013 \\
\hline Piperacillin & 3 & $(17)$ & 10 & $(12)$ & 0.58 \\
\hline Renal replacement therapy & 3 & $(17)$ & 3 & (4) & 0.032 \\
\hline Renal impairment & 11 & $(61)$ & 27 & (32) & 0.021 \\
\hline \multicolumn{6}{|l|}{ Indication for linezolid } \\
\hline Intra-abdominal infection & 5 & $(28)$ & 9 & (11) & 0.056 \\
\hline Cystic fibrosis exacerbation & 3 & $(17)$ & 23 & (27) & 0.34 \\
\hline Urinary tract infection & 2 & $(11)$ & 19 & (23) & 0.27 \\
\hline Bacteremia of unknown origin & 2 & (11) & 13 & (15) & 0.64 \\
\hline Pneumonia & 2 & $(11)$ & 5 & (6) & 0.43 \\
\hline Osteomyelitis & 3 & $(17)$ & 2 & (2) & 0.011 \\
\hline Skin and soft-tissue infection & 1 & (6) & 7 & (8) & 0.69 \\
\hline Meningitis & 0 & (0) & 1 & (1) & 0.64 \\
\hline Other & 0 & (0) & 5 & (6) & 0.29 \\
\hline
\end{tabular}

LMWH = low-molecular-weight heparin, SD = standard deviation, UFH = unfractionated heparin.

*Except where indicated otherwise.

Table 2. Laboratory Data for Patients with and without Thrombocytopenia

\begin{tabular}{|c|c|c|c|c|c|}
\hline \multirow[b]{2}{*}{ Variable } & \multicolumn{4}{|c|}{ Group; No. (\%) of Patients } & \multirow[b]{2}{*}{$p$ Value } \\
\hline & \multicolumn{2}{|c|}{$\begin{array}{c}\text { With } \\
\text { Thrombocytopenia } \\
(n=18)\end{array}$} & \multicolumn{2}{|c|}{$\begin{array}{c}\text { Without } \\
\text { Thrombocytopenia } \\
(n=84)\end{array}$} & \\
\hline & & & & & \\
\hline SCr elevated* & 9/18 & (50) & $23 / 84$ & (27) & 0.061 \\
\hline Platelets $<150 \times 10^{9} / \mathrm{L}$ & $3 / 18$ & $(17)$ & $5 / 84$ & (6) & 0.12 \\
\hline Albumin $<35 \mathrm{~g} / \mathrm{L}$ & $12 / 12$ & $(100)$ & $43 / 56$ & (77) & 0.063 \\
\hline $\mathrm{CRP}>3.1 \mathrm{mg} / \mathrm{L}$ & $5 / 6$ & (83) & $52 / 53$ & (98) & 0.058 \\
\hline Total bilirubin $>20 \mu \mathrm{mol} / \mathrm{L}$ & $0 / 15$ & (0) & $5 / 65$ & (8) & 0.27 \\
\hline \multicolumn{6}{|l|}{ Most aberrant value } \\
\hline SCr elevated* & $11 / 18$ & (61) & $27 / 84$ & $(32)$ & 0.021 \\
\hline Platelets $<150 \times 10^{9} / \mathrm{L}$ & $15 / 18$ & (83) & $10 / 84$ & $(12)$ & $<0.001$ \\
\hline$C R P>3.1 \mathrm{mg} / \mathrm{L}$ & $9 / 10$ & (90) & $31 / 33$ & (94) & 0.67 \\
\hline Total bilirubin $>20 \mu \mathrm{mol} / \mathrm{L}$ & $2 / 10$ & (20) & $2 / 28$ & (7) & 0.26 \\
\hline
\end{tabular}

$\overline{\mathrm{CRP}}=\mathrm{C}$-reactive protein, $\mathrm{SCr}=$ serum creatinine.

*For women, elevation of SCr was defined as > $90 \mu \mathrm{mol} / \mathrm{L}$; for men, elevation of SCr was defined as > $100 \mu \mathrm{mol} / \mathrm{L}$. 
these patients, our sample size would have been too small to allow analysis of any contributing risk factors. Previous studies assessing risk factors for linezolid-induced thrombocytopenia did not record information about concomitant use of LMWH and UFH. ${ }^{1,5-9,15,20-22}$ It is possible that concomitant UFH is a risk factor for linezolid-induced thrombocytopenia. Conversely, this finding may be related to other factors. We cannot exclude the possibility that patients experienced heparin-induced thrombocytopenia. However, the rates of this form of thrombocytopenia would likely have been low in our study, given that previously reported rates are only up to $5 \%$ of patients receiving UFH and less than $1 \%$ of those receiving $\mathrm{LMWH} .{ }^{25}$ In addition, it is notable that one of the patients with thrombocytopenia had received only 2 doses of UFH. A third possibility is that this finding is related to renal impairment. UFH is used in place of LMWH for prophylaxis of venous thromboembolism in patients with renal impairment. The higher frequency of thrombocytopenia among patients receiving concomitant UFH may relate to these patients having renal impairment, which would place them at higher risk of linezolidinduced thrombocytopenia.

The frequency of thrombocytopenia was also higher among patients with osteomyelitis. This outcome may have been related to the longer duration of linezolid treatment required for this type of infection. Only 5 of the 102 patients had osteomyelitis, and it has not been noted as a risk factor in previous studies. This result is likely a chance finding.

Other reported risk factors for linezolid-induced thrombocytopenia identified by previous investigators have included elevated baseline leukocyte concentration, ${ }^{6}$ low baseline leukocyte concentration, ${ }^{8}$ low baseline serum protein concentration, ${ }^{8}$ higher daily weight-based dose, ${ }^{1}$ chronic liver disease, ${ }^{13}$ and previous vancomycin use. ${ }^{14}$ Because of the impact of infection on leukocyte count, changes in leukocyte concentrations were not evaluated. Data for serum protein concentration were not available for most of our patients. No difference in weight-based dose (milligrams per kilogram of body weight) was noted between the groups. Similarly, there was no difference in total bilirubin between the groups, but we did not assess patients' histories for chronic liver disease. As a result, chronic liver disease as a potential risk factor was not sufficiently assessed. The groups did not differ in terms of previous vancomycin use.

Several limitations should be considered when interpreting our results. First, the sample size was small (102 patients). Our extensive exclusion criteria limited the sample size, but were necessary to help rule out other causes of thrombocytopenia. Second, data were not available for all risk factors for all patients; for example, we were unable to analyze serum protein as a risk factor. Finally, plasma linezolid concentrations were not investigated. This study did not address the risk for further decrease in platelet concentration among patients who had thrombocytopenia at the time of linezolid initiation, nor did it consider the contribution of other potential mechanisms for a decrease in platelet concentration.

\section{CONCLUSION}

The real-life frequency of new-onset thrombocytopenia among patients receiving linezolid for a minimum of 5 days was $17.6 \%$. Notable risk factors for linezolid-induced thrombocytopenia included renal impairment, renal replacement therapy, and prolonged duration of therapy (although some patients experienced thrombocytopenia within 14 days of treatment). Clinicians should monitor patients for linezolid-induced thrombocytopenia throughout therapy. Particular attention should be paid to patients with renal impairment.

\section{References}

1. Natsumoto B, Yokota K, Omata F, Furukawa K. Risk factors for linezolidassociated thrombocytopenia in adult patients. Infection. 2014;42(6): 1007-12.

2. Johnson PC, Vaduganathan M, Phillips KM, O'Donnell WJ. A triad of linezolid toxicity: hypoglycemia, lactic acidosis, and acute pancreatitis. Proc (Bayl Univ Med Cent). 2015;28(4):466-8.

3. ${ }^{P}$ Zyvoxam ${ }^{\circledR}$ [linezolid product monograph]. Kirkland (QC): Pfizer Canada, Inc; 2018.

4. Canadian Antimicrobial Resistance Surveillance System: 2017 Report. Ottawa (ON): Public Health Agency of Canada; 2017.

5. Hirano R, Sakamoto Y, Tachibana N, Ohnishi M. Retrospective analysis of the risk factors for linezolid-induced thrombocytopenia in adult Japanese patients. Int J Clin Pharm. 2014;36(4):795-9.

6. Ichie T, Suzuki D, Yasui K, Takahashi H, Matsuda M, Hayashi H, et al. The association between risk factors and time of onset for thrombocytopenia in Japanese patients receiving linezolid therapy: a retrospective analysis. J Clin Pharm Ther. 2015;40(3):279-84.

7. Takahashi Y, Takesue Y, Nakajima K, Ichiki K, Tsuchida T, Tatsumi S, et al. Risk factors associated with the development of thrombocytopenia in patients who received linezolid therapy. J Infect Chemother. 2011;17(3):382-7.

8. Hanai Y, Matsuo K, Ogawa M, Higashi A, Kimura I, Hirayama S, et al. A retrospective study of the risk factors for linezolid-induced thrombocytopenia and anemia. J Infect Chemother. 2016;22(8):536-42.

9. Niwa T, Suzuki A, Sakakibara S, Kasahara S, Yasuda M, Fukao A, et al Retrospective cohort chart review study of factors associated with the development of thrombocytopenia in adult Japanese patients who received intravenous linezolid therapy. Clin Ther. 2009;31(10):2126-33.

10. Tajima M, Kato Y, Matsumoto J, Hirosawa I, Suzuki M, Takashio Y, et al. Linezolid-induced thrombocytopenia is caused by suppression of platelet production via phosphorylation of myosin light chain 2. Biol Pharm Bull. 2016;39(11):1846-51.

11. Wang TL, Guo DH, Bai Y, Wen K, Han WY, Wang R. Thrombocytopenia in patients receiving prolonged linezolid may be caused by oxidative stress. Clin Drug Investig. 2016;36(1):67-75.

12. Bernstein WB, Trotta RF, Rector JT, Tjaden JA, Barile AJ. Mechanisms for linezolid-induced anemia and thrombocytopenia. Ann Pharmacother. 2003;37(4):517-20.

13. Ikuta SI, Tanimura K, Yasui C, Aihara T, Yoshie H, Iida H, et al. Chronic liver disease increases the risk of linezolid-related thrombocytopenia in methicillin-resistant Staphylococcus aureus-infected patients after digestive surgery. J Infect Chemother. 2011;17(3):388-91.

14. Rao N, Ziran BH, Wagener MM, Santa ER, Yu VL. Similar hematologic effects of long-term linezolid and vancomycin therapy in a prospective observational study of patients with orthopedic infections. Clin Infect Dis. 2004;38(8):1058-64

15. Nukui Y, Hatakeyama S, Okamoto K, Yamamoto T, Hisaka A, Suzuki H, et al. High plasma linezolid concentration and impaired renal function 
affect development of linezolid-induced thrombocytopenia. J Antimicrob Chemother. 2013;68(9):2128-33.

16. Matsumoto K, Takeshita A, Ikawa K, Shigemi A, Yaji K, Shimodozono Y, et al. Higher linezolid exposure and higher frequency of thrombocytopenia in patients with renal dysfunction. Int J Antimicrob Agents. 2010;36(2): 179-81.

17. Waldrep TW, Skiest DJ. Linezolid-Induced anemia and thrombocytopenia. Pharmacotherapy. 2002;22(1):109-12.

18. Attassi K, Hershberger E, Alam R, Zervos MJ. Thrombocytopenia associated with linezolid therapy. Clin Infect Dis. 2002;34(5):695-8.

19. Moraza L, Leache L, Aquerreta I, Ortega A. Linezolid-induced haematological toxicity. Farm Hosp. 2015;39(6):320-32.

20. Kato H, Hamada Y, Hagihara M, Hirai J, Yamagishi Y, Matsuura K, et al. Bicytopenia, especially thrombocytopenia in hemodialysis and nonhemodialysis patients treated with linezolid therapy. I Infect Chemother. 2015;21(10):707-12.

21. Lin YH, Wu VC, Tsai IJ, Ho YL, Hwang JJ, Tsau YK, et al. High frequency of linezolid-associated thrombocytopenia among patients with renal insufficiency. Int J Antimicrob Agents. 2006;28(4):345-51.

22. Matsumoto K, Shigemi A, Takeshita A, Watanabe E, Yokoyama Y, Ikawa K, et al. Analysis of thrombocytopenic effects and population pharmacokinetics of linezolid: a dosage strategy according to the trough concentration target and renal function in adult patients. Int J Antimicrob Agents. 2014; 44(3):242-7.

23. Wu AV, Wang Y, Wang C, Tsai I, Wu K, Hwang J, et al. High frequency of linezolid-associated thrombocytopenia and anemia among patients with end-stage renal disease. Clin Infect Dis. 2006;42(1):66-72.

24. Brier ME, Stalker DJ, Aronoff GR, Batts DH, Ryan KK, O'Grady M, et al. Pharmacokinetics of linezolid in subjects with renal dysfunction. Antimicrob Agents Chemother. 2003;47(9):2775-80
25. Heparin-induced thrombocytopenia (HIT). In: Clinical guides. Whitby (ON): Thrombosis Canada; 2015 [cited 2017 Nov 1]. Available from: https://thrombosiscanada.ca/clinicalguides/\#

Nicole Giunio-Zorkin, BSC, PharmD, ACPR is a Clinical Pharmacist with St Paul's Hospital, Vancouver, British Columbia.

Glen Brown, BSC(Pharm), PharmD, FCSHP, BCPS, BCCCP, is a Clinical Pharmacy Specialist in Critical Care with St Paul's Hospital, Vancouver, British Columbia. He is also an Associate Editor with the Canadian Journal of Hospital Pharmacy.

Competing interests: None declared.

\section{Address correspondence to:}

Dr Nicole Giunio-Zorkin

St Paul's Hospital

1081 Burrard Street

Vancouver BC V6Z 1 Y6

e-mail: nicole.giuniozorkin@providencehealth.bc.ca

Funding: None received.

\section{ON THE FRONT COVER}

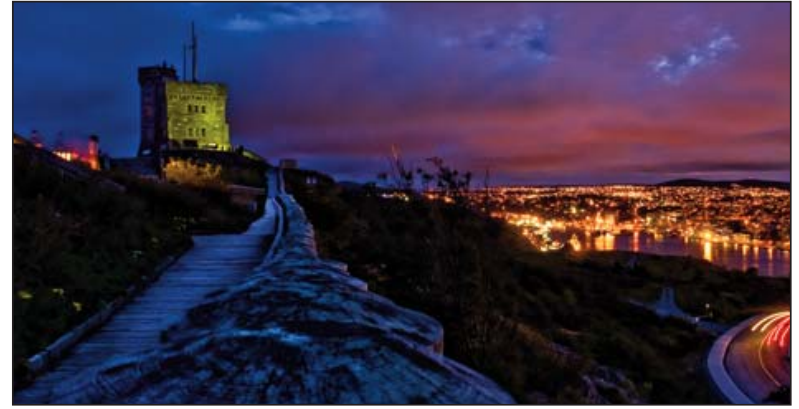

The CJHP would be pleased to consider photographs featuring Canadian scenery taken by CSHP members for use on the front cover of the Journal. If you would like to submit a photograph, please send
Signal Hill St John's, Newfoundland and Labrador

Signal Hill, positioned strategically at the mouth of St John's Harbour, has been the site of many fortifications since the 17 th century. On December 12, 1901, the first transatlantic wireless transmission was received at Signal Hill by Guglielmo Marconi. Today, it is a National Historic Site of Canada. Joshua Bryant took the cover photograph with a Nikon d5100 in late summer, 2013. Joshua is a Clinical Pharmacist with Northwest Telepharmacy Solutions.

an electronic copy (minimum resolution $300 \mathrm{dpi}$ ) to publications@cshp.pharmacy. 